\title{
The Salt Daemon
}

\author{
Susan Courtney, Ph.D.*
}

\begin{abstract}
Jung's inquiry into the interconnectivity of psyche and matter and body and soul included alchemical studies and his psychoid theory, which was loosely based on the dynamics of the electromagnetic field. Using Jung's presentational methodology in which psyche and physis are held evenly, this study presents salt as a liminal, psychophysical substance animating body and soul, world and anima mundi. Salts dissociate in the solutions of the body and sea, creating the electrolytic spark of life, just as alchemical sal in solutio signals a dissociative, incoherent yet psychoactive state, which seeks recrystallization-coagulatio or coherence. The rhythmic movement between incoherence and coherence is self-organized by a fieldlike guiding force of the psychoid that I call the salt daemon, which is entangled with other such salt spirits. The salt daemon's alternation between uneasiness and calm - the sensate conscienceworks toward increasingly differentiated body-soul coherence: the alchemical sal sapientiae, embodied wisdom.
\end{abstract}

Several years ago, I followed the Clackamas River toward its source in the Cascade Range of Oregon, hoping to find in this wilderness a living image evoking the unity of psyche and matter - a mysterium to which Jung had devoted much of his career. While I sat in quiet contemplation, I heard the word salt, in a faint, feminine voice, rise like a mist from the river, and an image moved across my mind's eye of salts leaching from the clay embankment and sparking and flashing in the flow of water. I felt called by salt, as if my body were in resonance with salt sparks of River.

The inner image of salt sparking in water led me to Jung's (1955/1963) essay on the alchemical sal in his opus, Mysterium Coniunctionis, in which salts dissociated in solutio hold a dynamic tension between physicality and a spiritual principle that works toward a state of fully differentiated, "maximal integration" of body and soul, psyche and matter (pp. 42, 188). For the alchemists, sal in solutio animates the body and world (p. 244), just as the salt solutions of the body and sea are electrolytic, electromagnetic, and animating. The tension of psychical and physical salt sparks is considered through characteristics of Jung's theory of the psychoid as it was loosely modeled on the electromagnetic field, an approach that carries certain risks, such as the subtle

*susancourtney9@gmail.com 
implication that psyche derives from physicality. For this reason, von Franz (1988/1992a) stated, Jung had avoided presenting physical processes parallel to psychical processes but had been convinced that connections of physis and psyche would eventually emerge, most likely in "a very unexpected place, where no one had anticipated it-in microphysics" (p. 2).

Edinger (1996) had described Jung's research methodology as presentational, to set empirical facts of the psyche side by side with observations of the material world, a holistic approach in which interconnections break through the horizon of psyche and physis (p. 11). Out of such a methodology - the even holding of a polarity or tension of opposites - might emerge new and unexpected perspectives, expanded self-awareness, greater depth of meaning, as well as a "living symbol" that unites the former polarity in a process that Jung (1921/1971) called the transcendent function (p. 480).

\section{Salt Daemon}

Holding depth psychological implications of the alchemical sal, of the electrolytic solution of dissociated salts, and of the electromagnetic field has brought out an image of a psychophysical, integrative dynamic that I call the salt daemon, an innate, selfpatterning, purposeful force that resonates within the feeling body and acts as an energetic connective tissue among sentient beings and between animated life and earth. The image of a salt daemon emerged from a meditation that took place at the edge of the estuary, where I saw in my mind's eye a person whose flesh and bones were dissolved in a matrix of sparks that flashed in response to sparks of the infusing sea mist. The aliveness of the personal salt mist was discernable but not separable from the aliveness of the salt spray: person and environment were woven in a complex, integrative dance of smaller and greater sparks of physicality and purposeful energy. Thus, the salt daemon is not a thing but an integrative flow, a perspective informed by Jung's (1961a) realization in his alchemical studies that the unconscious is not a place or thing but a transformative and purposeful dynamic that moves toward a state of intrapersonal and collective unity (p. 209).

Although guiding spirits had been alive in humans, animals, and the landscape in ancient and medieval times, the Age of Reason had effectively deanimated these "sparks of the World Soul," the demons, gods, and goddesses, the "messengers from heaven and monsters of the abyss" (Jung, 1945/1980, pp. 591-593). Images of autonomous, psychical agencies in nature and within the dark (unconscious) side of human nature were brought back to Western discourse in the early 19th century through the German 
Romantic movement, which held a sense of the "universe as a living organism endowed with a soul pervading the whole and connecting its parts" (Ellenberger, 1970, pp. 7778). Among the ideas the Romantics resurrected was the daemon, a will or directing agency of the unconscious body, a vital élan or genii, a creative, energetic force motivating human feelings and imagination but extending beyond the person into nature (Jung, 1946/1960b, p. 171); (Ellenberger, 1970, pp. 207-208). To Jung's (1928/1953c) thinking, the integrative, directing agency or inner daemon held two aspects: a "transpersonal control-point" appearing in dreams and visions in numinous images of the archetypal psyche, and a "guiding function" that works through the subterranean psyche extending into dynamic instinctual functions of the body (emphasis in original, pp.134-135, 135n). Jung (1946/1960b) surmised that the unconscious will parallels the conscious mind by having its own dark or subliminal ways of thinking, feeling, and perceiving; its own insights, memories, imaginative faculty, judgment, and selforganization, whether or not these activities are noticed by the conscious mind (pp. 172173). The inner daemon, for Jung (1958/1964a), a spirit, life force, or "manifestation of mana, of the extraordinarily powerful," moves not only through the person and among people but across the landscape, mediated by a fundamental, fieldlike, numinous rapport called participation mystique, an interpenetration of personal and transpersonal emotional experience within a unitary state of being-unus mundus (p. 448, 452). Hillman (1996) held a deep regard for the motivating factor of the daimon as a lifelong guardian of soul entwined with body, a unique and innate image perceivable in the effects of its unconscious impulses, intuitions, decisions, and actions (pp. 6-10). For Hillman, this daimon is less an evolving process than a gestalt that preexists and stands outside of linear time, holding "all in the copresence of today, yesterday, and tomorrow," which can be intuited as one's "sense of calling, that essential mystery at the heart of each human life" (pp. 6-7,12, 245).

Treatises of medieval alchemy had portrayed a salt spirit, a wingless black bird carrying bitterness in its throat, which Jung (1955/1963) interpreted as salty grains of emotions and memories trapped in the body whose gall or sting provides "the strongest incentive to a differentiation of feeling," thus impelling the reluctant adept through the painful opus (pp. 194-197, 248). The black bird, which the alchemists called the "'servant and messenger of the inner word [logos]," but which "Christianity regarded as demonic," reveals its inner knowledge as the transformational work continues, leading to a more integrative state of mind and body called sal sapientiae, salted sapience (pp. 194-196). Not merely a fleeting moment of personal consciousness, sal sapientiae is an emergent, self-sovereign, and embodied intelligence, as well as a ubiquitous life-spirit 
that is inseparable from the world and the anima mundi - the world soul that "animates the whole cosmos" (Jung, 1961a, p. 211), and which was composed, the alchemists specified, of inorganic, stellar salt-sparks (Jung, 1955/1963, pp. 240, 244).

The thesis of a salt daemon is presented initially through characteristics of salt and alchemical sal, Jung's psychoid, and observations from electromagnetism, followed by specific points of their convergence. The intuitive and sensate perception of a salt daemon is then deepened through perspectives of coherence, entanglement, and the conscience.

\section{Salt}

The concept of a salt daemon that inhabits the body yet extends into the world was strongly influenced by Jung's (1955/1963) synthesis of ancient, Gnostic, biblical, and alchemical correspondences to salt, in which are found images of the transformational movements called solutio and coagulatio that symbolize the dissociation and integration of body and soul in the lifelong process of finding one's self ( $\mathrm{pp}$. xiv-xv). The oldest known symbol for salt was the single dot or salt-point, which symbolized, among other concepts, the first sparks of fire or light or consciousness in potentia, the spark of the anima mundi, the magnetic pole of the body and earth that was the "mysterious creative center" of the four directions that encompass the world, the beginning and return points of time and the realms beyond time-keeping, and the "indivisible" center of the cosmos (pp. 45-47, 244). The salt-point was the apex of intelligence: the divine nous - a cosmic principle or quintessence synonymous with God and the sphere surrounding God (p. 244). Salt was the prima materia, the original matter holding the matrix of all potentiality, interpreted depth psychologically as bitter, undifferentiated, and despised grains of experience that lie inert and buried in the body and earth, like stones that obstruct the free flow of spirit (Edinger, 1985, pp. 47-48). Sal was not only the beginning point but the endpoint of the alchemical opus, the gold, lapis, or philosopher's stone, which Jung (1955/1963) understood as a state of individuation or total union that he called the self - the integration of the personal will within an immanent, autonomous, higher Will (pp. 47, 244, 544).

Jung (1955/1963) encapsulated sal in solutio, the sparks of life and transformation in the body and the world, through the integrative, free-flowing, "feminine principle of Eros, which brings everything into relationship, in an almost perfect way" (emphasis in original, p. 241). Eros evoked for Jung (1951/1959a) not the Greco-Roman masculine god but an "intuitive" concept of a "connective quality" or life force of the feminine 
feeling function that holds a psychical tension with the masculine "discrimination and cognition associated with Logos" (p. 14). Far more expansive than the Freudian instinctual sex drive, Jung (1914/1961b) perceived in Eros a "cosmogonic principle" of "psychic energy," a feeling of "empathy and adaptation" that flows through the sensate body and extends into meaningful interconnectivity or compassio among people (p. 285). In her capacity as mediatrix of nonrational, emotional life, Eros corresponds to the alchemical sal through the image of Luna, lunar consciousness, the ebb and flow of darkness and reflected light that draws out the feeling function of the body, balancing the rational solar consciousness of Logos within a necessary conjunction of feeling and thinking that unites body and soul in embodied, grounded wisdom (Jung, 1955/1963, pp. 180, 248-249).

Hillman (1979/2010b), in his essay, "The Suffering of Salt," acknowledged Jung's scholarly work on the alchemical sal yet looked to "substantiate" the cosmic principle of salt by drawing out its "commonly recognizable experience"- the saltiness of life, which is "essential to the embodiment of our psychic nature" (p. 55). Similarly, the idea of the salt daemon stands on the platform of Jung's (1955/1963) psychological interpretation of alchemical sal held in balance with certain phenomena of salts in the body and nature.

\section{The Psychoid}

The salt daemon embodies the dynamic tension of psyche and matter that Jung (1958/1964b) called the psychoid, an unknown "factor" that lends "matter a kind of 'psychic' faculty and the psyche a kind of materiality" (p. 411). Although Jung had not originated the idea of the psychoid, he expanded its sphere from an organ- or organismbased psychical agency into a principle of interconnectivity governing "matter in general. ... [in which] all reality would be grounded on an unknown substrate" (p. 411). Jung's (1946/1960b) psychoid was not equivalent to the unconscious psyche but was the deepest extension of psyche into the inorganic matter of the body and earth as well as the highest extension of psyche into the "autonomous" sphere of the archetypes (p. 183); the psychoid is then a centering force that "acts like a magnet on the disparate materials and processes of the unconscious and gradually captures them as in a crystal lattice" (Jung, 1944/1953b, p. 217). Jung (1946/1960b) surmised that the lower, physiological, and upper, archetypal ranges of the psychoid were ultimately "two different aspects of one and the same thing," touching and not-touching at some point outside the constraints of consciousness, time, and space (pp. 206, 215). 
Jung (1934/1959b) associated the psychoid function with the "realm" of the sympathetic division of the involuntary (unconscious) autonomic nervous system, where "the soul of everything living begins; where I am indivisibly this and that; where I experience the other in myself and the other-than-myself experiences me" (emphasis in original, pp. 18-22) (salts in solution and the nervous system are discussed below). Conforti (2013) expressed Jung's psychoid realm as an "underlying, generative field from which psyche and matter arise" (pp. 48-49), while Cambray (2009) described the interrelationality of the psychoid as an "empathic resonance" holding characteristics of vibration, frequency, and intensity, which create an "attunement among elements or agents in a field" (pp. 68-70). Von Franz (1974) ascribed the characteristic of rhythmicity to the psychoid, which is evident in repetitive and ritual movements such as dance that create a felt sense of affinity with others, while arhythmicity indicates a degree of body-mind dissociation called depersonalization, which might extend to dissociation of the person from the world, called derealization (p. 158). In recent decades, neuroscience has observed a number of oscillating, self-organizing, involuntary responses to inner and environmental stimuli that have been termed rhythmic entrainment or resonant synchrony (Thaut, McIntosh \& Hoemberg, 2014, More Clinical Applications of Entrainment, para. 2). Such rhythms are mediated through the sympathetic and parasympathetic divisions of the autonomic nervous system (Marieb \& Hoehn, 2007, p. 459). Out of the contemplation of rhythmicity and empathic resonance of the psychoid alongside observations from mainstream sciences of a rhythmic synchrony between the body and the environment has emerged an image of the salt daemon's purposeful oscillation toward greater harmony of body and soul, which leads to greater harmonic resonance with others and the world.

\section{Electromagnetism}

Jung had explored the intersection of body and soul, psyche and matter, through his interests in Chinese metaphysics, the German Romantic idea of a preestablished harmony of all things, electromagnetism, the spacetime gravity field, and quantum field theory (among other influences), all of which informed his theories of the psychoid and synchronicity (Haule, 2011, p. 85). The idea of a field of energy originated with Michael Faraday's 1849 observation that a moving electrical current is always magnetized and produces sparks (light radiation) that arc over great distances without connecting wires, like an invisible blanket of magnetized electricity-a phenomenon he called electromagnetism. Although subject to interference, the electromagnetic field extends 
indefinitely in dynamic interaction with other such fields as well as with matter, which led Faraday to infer an invisible "unity in all types of physical interaction," a belief that Einstein later shared (Moring, 2000, p. 84). The quantum electromagnetic field of salts in solution (electrolytes) is more extensive and more interactive than nonionic atoms' fields due to the electrolytes' imbalance of positive proton and negative electrons, which creates a greater charge and therefore a larger field (Marieb \& Hoehn, 2007, pp. 25-26). Exactly how a moving (not static) electrical current creates a magnetized field is not known, as if electromagnetism were a mysterium coniunctionis, like the psychoid and the ancient, underlying, unified world of matter, psyche, and spirit called unus mundus, phenomena that Jung (1945/1968a) called just so (p. 272). The just so psychoid realm might be set side by side with physicist Weinberg's (1977) description of electromagnetism as a thing-in-itself, an "independent inhabitant of our universe, with as much reality as the particles on which it acts" (p. 19).

Electromagnetism drew Jung's attention as a model for the psychoid in part due to its emergent phenomena of electromagnetic radiation (the light spectrum), given, as Jung often observed, that light and color have long been associated with states of consciousness. Jung (1946/1960b) perceived an electromagnetic polarity of the invisible, lower, warm infrared radiation, symbolizing psyche reaching into the inorganic matter of body and earth; and the upper, invisible, cool ultraviolet radiation that symbolizes psyche reaching into transpersonal spirit; together, chthonic infrared and numinous ultraviolet hold a dynamic tension that "establishes the existence" of the psychoid (pp. 181-183, 211-212). Von Franz (1988/1992a) regarded Jung's metaphor of electromagnetism for the psychoid as a holistic field approach that does not focus exclusively on the brain but places the psychoid realm "within the whole bodily sphere" and specifically in inorganic matter (pp. 3-4). In this schema, the infrared pole, psyche interwoven with somatic processes, and the ultraviolet pole of numinous archetypes “constitute a unitary reality” (pp. 9, 11). In von Franz's (1972/1998) comparison of the unified field of psyche and matter to integrative electromagnetic fields of all visible and invisible phenomena, she perceived a creative force in the image of an "inter-human Eros, the pre-conscious ground of all communication and community among" people that flows throughout the web of nature (emphasis in original, pp. 124-125,138).

\section{Convergence of Salt, the Psychoid, and Electromagnetism}

Although connections between alchemical salt, the psychoid substrate, and the electromagnetic field in Jung's writings are more implicit than explicitly stated, I suggest 
six points of their possible convergence: inorganic substrate, polarity, magnetism, dynamic field, self-organization, and animating sparks of sentience. Each of these characteristics are strands of a web of a meaningful psychophysical intelligence of the unconscious body and soul that is experienced through inner coherence and incoherence, and entanglement with others and the environment, which creates the phenomenon of the conscience - a felt oscillation of the salt daemon.

Inorganic substrate. The salt daemon evokes a dynamic conjunction of an inorganic substrate (salts and water) of the body and personal soul on the one hand and the world and transpersonal psyche on the other. Alchemists had worked primarily if not exclusively with inorganic materials, especially the saltwater solution out of which emerges the salt stone, an inner "symbol of wholeness" inseparable from a transpersonal, "inorganic," "more objective point of view" (Jung, 1955/1963, pp. 216-217). The salt stone was the "secret of alchemy," the goal of the opus, the lapis or philosopher's stone, which has "roots" in the "chemical elements" of the body and earth (Jung, 1948/1968b, p. 195). In fact, when the total integration of spirit and matter is realized in the fully individuated self, "since the cosmos is infinitely greater than we are, we shall have been assimilated by the inorganic" (p. 239). Assimilation by the inorganic calls to mind the interactive electromagnetic fields of the human body that are inseparable from larger fields, such as the geo-electromagnetic field that emanates from and envelops the planet, which is itself integrated with the interplanetary magnetic field.

The unity of spirit and matter within an inorganic realm has been recognized in the contemporary movement of Earth-Spirituality, in which all of the Earth's inhabitants might speak to us of "the grand mysteries of existence" if only the human would unlock the inner senses that perceive voices both organic and inorganic (Berry, 1999, pp. 17, 25). Earth-Spirituality carries forward the work of paleontologist, scholar, and mystic Pierre Teilhard de Chardin (1968/1999), who portrayed a "spark of spirit" immanent in all matter - even inorganic matter, which is "certainly animate in its own way" (p. 63).

Polarity. Within the salt solutio lies potential energy that emerges from alchemical salt's polarized tension, its "paradoxical double nature" that is composed of the "most potent set of opposites imaginable" (Jung, 1955/1963, p. 250). Salt's dynamic bipolarity exemplified what Jung called the living, "generative force" of psychoid processes (in Jacobi, 1957/1959, p. 50). In Jung's (1917/1953a) words, "everything rests on an inner polarity; for everything is a phenomenon of energy" (p. 75). The often-polarized tension between emotionality and rationality, body and mind, generates a psychophysical integrative energy that can be envisioned in the uroboric image of the dragon eating its tail, which the alchemists expressly identified with salt (Jung, 1955/1963, pp. 251, 365). 
The spirit of alchemy began in the "chaotic waters" before the "separation of the opposites and hence before the advent of consciousness" (Jung, 1955/1963, p. 197). Jung (1927/1960a) surmised that the psyche "must exhibit organs or functional systems that correspond to regular physical events" of "primordial times," although the psychical systems are since independent of the physical event (p. 153). As an example, the alternation of day and night, light and dark, solar and lunar, "must have imprinted themselves on the psyche," since its "organization must be intimately connected with environmental conditions" (Jung, 1946/1960b, pp. 152-153). In the body and estuary, inflowing fresh water stirs up and dissociates inert salt compounds into their intrinsic electrolytes, polarizing the (electromagnetic) salt solution. Perhaps the polarity of salt ions in the primordial estuary, which has been proposed as the original cause and place of the spark of neural activity that led to animal life, was the original imprinter of polarity on the psychoid.

Magnetism. In Gnostic and alchemical doctrine, salts fill a magnetic pole that acts like a centering force of body and earth, soul and anima mundi, in which "everything hangs together with everything else" (Jung, 1951/1959a, pp. 133-136, 143). The salts of the magnetic pole draw together earth and cosmos, which means that no somatic experience is ultimately separable from the realm of spirit (pp. 185-188). Jung's (1918/1964c) understanding of the interconnectivity of psyche and matter, the psychoid, was influenced by Anton Mesmer's theory of animal magnetism that extends throughout the universe (p. 15). Mesmer had envisioned a medium that was both energetic and physical and which flowed through the person, between people, and through the earth and sky, a notion that was hotly debated in its time because it proposed that an invisible, magnetic force exists everywhere and has an effect on solid matter (Ellenberger, 1970, pp. 62-63). In 1820, five years after Mesmer's death, the Danish physicist Hans Oersted discovered that a moving electrical current is always magnetized, an observation that led over time to the discoveries of the electromagnetic field, quantum electromagnetism, the geomagnetic field, the interplanetary magnetic field, and electromagnetic plasma, which comprises $99.99 \%$ of the known Universe (Evans \& Heller, 2003, p. 245).

The idea of a salt daemon rests on the premise of a magnetic resonance of the body's salt solution that is interactive with the web of all sentient life and inorganic matter. Because the planet's spin (due to flowing rivers of molten iron salts below the Earth's surface) creates a powerful geomagnetic field, "everything around us is penetrated by magnetic lines of force - including the page you are currently reading and, indeed, your whole body" (Evans \& Heller, 2003, pp. 62, 245). Research suggests that many organisms, including elephants, honey bees, blind mole rats, fin whales, hammerhead 
sharks, salmon, and sea turtles are in resonance with the geomagnetic field for purposes such as migratory orientation and geophysical positioning (Arnason, Hart, \& O'ConnellRodwell, 2002, p. 126). In the last fifty years or so, researchers have investigated the possibility that the human biomagnetic field responds to environmental electromagnetic fields (Evans \& Heller, 2003, p. 188); a study from Australia found a "clinically meaningful" coincidence of suicides of women during "periods of geomagnetic storm activity," suggesting that the psychical state is affected by ambient magnetism (Berk, Dodd, \& Henry, 2006, p. 151).

Dynamic field. Although the idea in the sciences of an energetic field dates to the mid-19th century, von Franz (1988/1992a) had discerned a "basic intuition for the modern idea of the force field" in the classical, Stoic idea of pneuma, a generative, organizing factor of matter, psyche, and spirit; a concept that influenced Jung's development of the psychoid realm and its dynamic organizing factors, the archetypes, which "do not swim around in the collective unconscious like pieces of bread in the soup, rather they are the whole soup at every point" (pp. 9, 12, 54-55). Jung had been influenced as well by William James's concept of the psychoid as a field phenomenon (von Franz, 1966/1992, pp. 293-294), adapted by Jung to a field of activated, magnetic nodal points or archetypes, which interact with other archetypes, influence body and soul across spacetime, and emit sparks of consciousness; acting, in short, very much like interactive electromagnetic fields (Jacobi, 1957/1959, p. 24). The concept of a field might be discerned in the alchemical salt solutio, the aqua permanens, depicted by Edinger (1985) as a transpersonal sea of knowledge and self-knowledge, a liquid lapis, which exists at no particular point but in every point of the psychoid substrate (pp. 7980). A salt solution might be seen as a field phenomenon inasmuch as its dissociated electrolytes create an ionic charge that arcs throughout the solution. Except for static electricity, everything material exists in interconnected charged fields, just as the fieldlike psychoid extends beyond the person into the environment.

Self-organizing. Salts and the salt daemon exist sui generis, forming and reforming out of a just so principle. Clumps of salts dissolved in water (electrolytic solution) create an unpredictable, interactive and integrative electromagnetic field, which is the deepest known organizing factor of observable phenomena, as it binds electrons around atomic nuclei to form atoms, determining the function of all matter (Ulaby, Michielssen, \& Ravaioli, 2010, pp. 12-14). The alchemical sal self-organizes out of the incoherent state of psychological solutio within an autonomous differentiating principle that leads to greater clarity and self-sovereignty in body and soul (Jung, 1955/1963, pp. 188-190). Hillman (1979/2010) perceived an essential "mystery" and 
"substantiality" in salt's self-organizing factor of crystallizing in and out of the watery interior state (p. 64). The integrative, self-organizing dynamic of the alchemical sal correlates to the functional aspect of the psychoid, which emerges from a preexistent, "meaningful orderedness" not subject to constraints of space and time and is "responsible for the organization of unconscious psychic processes of the entire body and of all phenomena" (Jung, 1952/1960c, pp. 436, 505-506). Since the psychoid "must be intimately connected with environmental conditions" (Jung, 1927/1960a, p. 152), its organizational attribute extends indefinitely, evident in numinous visions and synchronicities-emergent phenomena that reveal meaningful patterns (Jung, 1946/1960b, pp. 231-232).

Animating spark of sentient life. The alchemical salt was a "ubiquitous" animating soul spark of the anima mundi that pours out into the body and everything in nature (Jung, 1955/1963, pp. 240-241). The salt sparks, called scintillae, hold two aspects; the dim, chthonic soul sparks of lumen that carry an irrational, "unexpected, unwanted, and incomprehensible" intelligence of the body that nevertheless "thinks, grasps, and comprehends" its own darkness; and the archetypal numen, brighter, more encompassing sparks of stellar quintessence (pp. xiv, 45-48, 189-192, 241, 255, 537). The dim salt sparks of lumen shine out of the lower, infrared range of the psychoid like fishes' eyes in dark water, while the ultraviolet range of transpersonal spirit emits the brighter archetypal lights of numen (Kalsched, 1996, p. 67). The spiritual numen magnetically draw from the body and earth the dimmer lights of lumen, dissociated fragments of sensate memories long buried in shame, bitterness, and fear, in a somatic separatio that is often felt as a loss of soul and that might lead to a temporary deanimated state, since the everyday sense of animation is composed of and organized by the little luminosities (Edinger, 1985, pp. 200-202). If the separatio of a luminosity from the unconscious body into consciousness is contained sufficiently within a strong spiritual or philosophical vessel of a constellating archetype, then the body is reanimated through a dawning realization of the numinous mana (pp. 202-203). Successive extractions of the hidden lumen by the numen creates the equilibrating movement of circulatio through which the adept spirals to higher and higher platforms of embodied self-knowledge, sal sapientiae, the integrated state of body, soul, and spirit that cultivates a compassionate rapport with others and a sense of oneness with nature (Jung, 1955/1963, p. 246).

Just as alchemical salt sparks in solutio animate the body and the earth, physical salts in solution dissociate to charged electrolytes that animate all innervated life. Every neural impulse and sensation, all perceptions, feelings, and thinking; all movement and visceral actions; all communications within the body and between the person and the 
world are mediated by electrolytes in the body's solution exchanging electrons across the permeable membrane of the neural system (Marieb \& Hoehn, 2007, pp. 40-41). Because it is the flow of electrons that innervates the body, each impulse of animation is necessarily electromagnetic (p. 26). The animated body exists within an incredible, dynamic matrix of entangled electromagnetic fields, created by the body's electrolytic solution but extending beyond the body into the world.

\section{The Feeling of the Salt Daemon}

The salt daemon oscillates along the magnetic pole of body and soul, which is not separable from the polarized field of psyche and matter - the surrounding world and anima mundi. Its oscillations work within a meaningful, intrinsic purposefulness toward harmony, which is reached only through waves of disharmony between the conscious mind and the uneasy body. The tension of disharmony and harmony, incoherence and coherence, is necessarily entangled with others and the environment, creating the dipolar feeling of the conscience of the person interwoven with the world.

Incoherence and coherence. The alternating and reconciling alchemical states of solutio and coagulatio hold a synergistic tension of incoherence and coherence. Coagulatio at the beginning of the opus symbolizes inert lumps of salts and clay composing the preanimated Adamic body as well as the fixations and inflexible complexes of the psyche (Edinger, 1985, pp. 82-85), in an overly focused, unimaginative state of coherence. Yet coagulatio holds meaning, spirit, and imagination in potentia, which might be released through dissolution in the incoherent state of solutio, "thereby restoring the original condition of chaos, so that a new and more perfect body can be produced" (Jung, 1951/1959a, p. 234), an insight that influenced Jung's personal and clinical practice called active imagination. In the depths of solutio, free-floating feelings and sparks of memories are drawn out from the nooks and crannies of the body and dissolved in the more diffuse, wavering, incoherent light just below the surface of the sea, in which new perspectives and understanding might crystallize. Paradoxically, one feels more alive when slightly incoherent and a little bit at sea, yet will feel drawn magnetically to a new sense of connectedness and coherence. The emergence of coherence begins within yet moves outward in an every-widening circle, as expressed by the 15th-century Italian scholar Pico della Mirandola:

Firstly there is the unity in things whereby each thing is at one with itself, consists of itself, and coheres with itself. Secondly there is the unity whereby one creature is united with the others and all parts of the 
world constitute one world. The third and most important (unity) is that whereby the whole universe is one with its Creator. (addition in original, Jung, 1946/1960b, p. 491)

Entanglement. Coherence between two objects is termed quantum entanglement, in which two seemingly discrete particles' electromagnetic fields act as if they were one and must be considered as one. I discern the idea of entanglement in many of Jung's myriad interests and influences, including the ancient and alchemical concept of unus mundus - a unified field of potential existence in which each point in the field is entangled with every other point; the Eastern philosophies of Tao and mana; Romantic notions of harmony or sympathy of all things; archetypal constellations of the collective unconscious; and Mesmer's universal, magnetic fluid. All of these influenced Jung's formulations of the psychoid and synchronicities, which are not subject to linear time and space and could be considered depth psychological theories of entanglement. Entanglement entails disentanglement, the psychological state of derealization or feeling alienated from the world. Aizenstat (1995) found that depth psychology has focused traditionally on the human psyche and has only obliquely considered the "interconnectedness between human experience and the creatures and things of our world," organic and inorganic (p. 95). He proposed that derealization can be healed by listening intently to the "life spark" of River, Tree, Wren, and Saltmarsh-voices of the anima mundi. British anthropologist Ingold (2006) also proposed that we might consider the human not as an organism separate from other organisms and the earth but as a "relational constitution of being" that is enmeshed in a planetary "domain of entanglement" of "interlaced lines of relationship" (pp. 12, 14). The relational constitution of being, for Jung (1955/1963), was an attribute of the feminine principle of Eros, found in the ebb and flow of the feeling function that extends into the numinous salt sparks of the anima mundi (pp. 179-180, 241).

Conscience: To know with. My meditations on the salt daemon brought out questions regarding its intrinsic motivation or guiding principles. Seeking a windsheltered spot in the alchemical laboratory of the estuary and entering a moment of active imagination, I heard the word conscience rise up into the misty air in a distinct, feminine voice - an experience as unexpected as hearing salt rise up from River. In his essay, "A Psychological View of Conscience," Jung (1958/1964a) had immediately dismissed Freud's idea of conscience as a consensus morality of religious dogma and familial and cultural values adapted by the ego when convenient (p. 439). To Jung's thinking, the conscience was an unconscious, morally indifferent, emergent feeling of the chthonic body ("dirt on the hands") that finds itself in "collision with a numinous archetype" (pp. 
437-439, 453). The word conscience means to know with, implying an other, an intrinsic polarity of the inner salt daemon; in fact, Jung noted that "there is scarcely any other psychic phenomenon that shows the polarity of the psyche in a clearer light than the conscience" (p. 447). Its organizational factor is a personality, will, or daemon of the psychoidal unconscious that is discernable in "emotional dynamism," a somatic differentiation of easiness (buoyancy) and uneasiness (sinking feeling), which might rise to the heavy seas of a psychomachia, a struggle between the "animal psyche" and spirit (pp. 439, 445-448, 451). Unlike the Freudian superego's imposition of morality on the conscientious ego, Jung's conscience preexists the subjective personality, arising from the fieldlike force of mana that "falls within the sphere of the collective unconscious" and acts like a reconciling, transcendent function of "reason and grace" (pp. 448, 454). When the conscious mind becomes aware of and negotiates with the inner salt daemon through the intuitive apperception and differentiation of feeling, an opportunity opens for integration of the emergent feelings - a salted, grounded, crystallization of higher wisdom.

Jung (1958/1964a) thought that the conscience, like the psychoid, is not an epiphenomenon of the body and brain but a "fundamental, essential, and numinous" transpersonal sphere that holds a "spaceless and timeless quality" (pp. 450, 452). Restless inner seas might be a response of one's inner salt daemon to another person's uneasy conscience, since the psychoid seems to be "active in the whole environment," and as such, "points to the sphere of the unus mundus, the unitary world" (p. 452). Thus the true or innate conscience - a felt intelligence of the body entangled with the world and the anima mundi-gives rise to the sensate perception of synchronistic phenomena, meaningful intersections of personal and interpersonal forces that extend beyond subjectivity, time, and space (p. 450).

\section{Salted Sentience}

The salt daemon might be felt as an inner estuary, the flux of fresh water and saltwater that moves to tides and currents, alternating between placid coherence and upwelling emotions. Even though the conscious, rational mind prefers the easy waters of a calm conscience, an inner intelligence with its own intentionality magnetically draws up bitter, coagulated salts from the body's seabed, creating an incoherent, even chaotic or terrifying solutio. The negotiation of the ebb and flow of emotions with the rational mind leaves one somewhat drained but standing on tentative new ground with broader horizons and a stronger sense of oneself in the world through a process that 
Freud had described as "'draining the sea-marshes to reclaim land"" (in Hillman, 1975, p. 26), and that Hillman (1975) termed "soul-making" (p. 23).

Hillman (1979/2010b) called the body a salt mine of subjective felt experiences that are mine, but the commonality of salt, the "common human experience," points also to the objective nature of psychical and physical salts (pp. 60-61). The salts of necessity, of injustice, of all archetypal energies, are embedded in the ground of our being yet might resonate with injustice in an other time and place, another person standing on another landmass, or perhaps, if coherence indeed works through the cosmos, another planet. The uneasiness and calming of the inner seas, therefore, works through the objective world, the saltmarsh of our origin, at whose edge the inner salt daemon expresses a healing and encompassing rhythm of the cosmogonic Eros.

\section{Works Cited}

Aizenstat, S. (1995). Jungian psychology and the world unconscious. In T. Roszak, M. Gomes, \& A. Kanner (Eds.), Ecopsychology: Restoring the Earth, healing the mind (pp. 95-96). San Francisco, CA: Sierra Club Books.

Arnason, B., Hart, L., \& O'Connell-Rodwell, C. (2002). The properties of geophysical fields and their effects on elephants and other animals. Journal of Comparative Psychology, 116, 123-132.

Berk, M., Dodd, S., \& Henry, M. (2006). Do ambient electromagnetic fields affect behavior? A demonstration of the relationship between storm activity and suicide. Bioelectromagnetics, 27(2), 151-155.

Berry, T. (1999). The great work: Our way into the future. New York, NY: Bell Tower.

Cambray, J. (2009). Synchronicity: Nature and science in an interconnected universe. College Station, TX: Texas A\&M University Press.

Conforti, M. (2013). Field, form, and fate: Patterns in mind, nature, and psyche. New Orleans, LA: Spring Journal Books.

Edinger, E. (1985) Anatomy of the psyche: Alchemical symbolism in psychotherapy. Chicago, IL: Open Court.

Edinger, E. (1996). The Aion lectures. Toronto, Ontario, Canada: Inner City Books.

Ellenberger, H. (1970). The discovery of the unconscious: The history and evolution of dynamic psychiatry. New York, NY: BasicBooks.

Evans, M., \& Heller, F. (2003). Environmental magnetism: Principles and applications of enviromagnetics. San Diego, CA: Elsevier Science (USA).

Haule, J. (2011). Jung in the 21st century (Vol. 2): Synchronicity and science. New York, NY: Routledge.

Hillman, J. (1975). Re-visioning psychology. New York, NY: HarperCollins.

Hillman, J. (1996). The soul's code. New York, NY: Random House. 
Journal of Jungian Scholarly Studies

Vol. 12, No. 1, 2017

Hillman, J. (2010a). Silver and the white earth. In Alchemical psychology (pp. 125-203). Putnam, CT: Spring. (Original work published 1980)

Hillman, J. (2010b). The suffering of salt. In Alchemical psychology (pp. 54-81). Putnam, CT: Spring. (Original work published 1979)

Ingold, T. (2006). Rethinking the animate, re-animating thought. Ethnos: Journal of Anthropology, 71, 920. doi: 10.1080/00141840600603111

Jacobi, J. (1959). Complex archetype symbol in the psychology of C. G. Jung (R. Manheim, Trans). Princeton, NJ: Princeton University Press. (Original work published 1957)

Jung, C. G. (1953a). On the psychology of the unconscious (R. F. C. Hull, Trans.). In H. Read et al. (Series Eds.), The collected works of C. G. Jung, (Vol. 7, 2nd ed., pp. 3-122). Princeton, NJ: Princeton University Press. (Original work published 1917)

Jung, C. G. (1953b). Psychology and alchemy (R. F. C. Hull, Trans.). In H. Read et al. (Series Eds.), The collected works of C. G. Jung (Vol. 12, 2nd ed.,). Princeton, NJ: Princeton University Press. (Original work published 1944)

Jung, C. G. (1953c). The relations between the ego and the unconscious (R. F. C. Hull, Trans.). In H. Read et al. (Series Eds.), The collected works of C. G. Jung, (Vol. 7, 2nd ed., pp. 123-244). Princeton, NJ: Princeton University Press. (Original work published 1928)

Jung, C. G. (1959a). Aion: Researches into the phenomenology of the self (R. F. C. Hull, Trans.). In H. Read et al. (Series Eds.), The collected works of C. G. Jung, (Vol. 9 pt. 2, 2nd ed.). Princeton, NJ: Princeton University Press. (Original work published 1951)

Jung, C. G. (1959b). Archetypes of the collective unconscious (R. F. C. Hull, Trans.). In H. Read et al. (Series Eds.), The collected works of C. G. Jung, (Vol. 9 pt. 1, 2nd ed., pp. 3-41). Princeton, NJ: Princeton University Press. (Original work published 1934)

Jung, C. G. (1960a). On the structure of the psyche (R. F. C. Hull, Trans.). In H. Read et al. (Series Eds.), The collected works of C. G. Jung, (2nd ed., Vol. 8, pp. 139-158). Princeton, NJ: Princeton University Press. (Original work published 1927)

Jung, C. G. (1960b). On the nature of the psyche (R. F. C. Hull, Trans.). In H. Read et al. (Series Eds.), The collected works of C. G. Jung, (Vol. 8, 2nd ed., pp. 159-234). Princeton, NJ: Princeton University Press. (Original work published 1946)

Jung, C. G. (1960c). Synchronicity: An acausal connecting principle (R. F. C. Hull, Trans.). In H. Read et al. (Series Eds.), The collected works of C. G. Jung, (Vol. 8, 2nd ed., pp. 417-531). Princeton, NJ: Princeton University Press. (Original work published 1952)

Jung, C. G. (1961a). Memories, dreams, reflections (A. Jaffé, Ed.). (C. Winston \& R. Winston, Trans.). New York, NY: Random House.

Jung, C. G. (1961b). Some crucial points in psychoanalysis: A correspondence between Dr. Jung and Dr. Loy (R. F. C. Hull, Trans.). In H. Read et al. (Series Eds.), The collected works of C. G. Jung, (Vol. 4, pp. 252-289). Princeton, NJ: Princeton University Press. (Original work published 1914)

Jung, C. G. (1963). Mysterium coniunctionis (R. F. C. Hull, Trans.). In H. Read et al. (Series Eds.), The collected works of C. G. Jung, (Vol. 14, 2nd ed.). Princeton, NJ: Princeton University Press. (Original work published 1955) 
Vol. 12, No. 1, 2017

Jung, C. G. (1964a). A psychological view of conscience (R. F. C. Hull, Trans.). In H. Read et al. (Series Eds.), The collected works of C. G. Jung, (Vol. 10, 2nd ed., pp. 437-455). Princeton, NJ: Princeton University Press. (Original work published 1958)

Jung, C. G. (1964b). Flying saucers: A modern myth (R. F. C. Hull, Trans.). In H. Read et al. (Series Eds.), The collected works of C. G. Jung, (Vol. 10, 2nd ed., pp. 307-433). Princeton, NJ: Princeton University Press. (Original work published 1958)

Jung, C. G. (1964c). The role of the unconscious (R. F. C. Hull, Trans.). In H. Read et al. (Series Eds.), The collected works of C. G. Jung, (Vol. 10, 2nd ed., pp. 3-28). Princeton, NJ: Princeton University Press. (Original work published 1918)

Jung, C. G. (1968a). The philosophical tree (R. F. C. Hull, Trans.). In H. Read et al. (Series Eds.), The collected works of C. G. Jung, (Vol. 13, pp. 251-349). Princeton, NJ: Princeton University Press. (Original work published 1945)

Jung, C. G. (1968b). The spirit Mercurius (R. F. C. Hull, Trans.). In H. Read et al. (Series Eds.), The collected works of C. G. Jung, (Vol. 13, pp. 191-250). Princeton, NJ: Princeton University Press. (Original work published 1948)

Jung, C. G. (1971). Psychological types (R. F. C. Hull, Trans.). In H. Read et al. (Series Eds.), The collected works of C. G. Jung, (Vol. 6, 2nd ed.). Princeton, NJ: Princeton University Press. (Original work published 1921)

Jung, C. G. (1980). Marginalia on contemporary events (R. F. C. Hull, Trans.). In H. Read et al. (Series Eds.), The collected works of C. G. Jung, (Vol. 18, pp. 591-603). Princeton, NJ: Princeton University Press. (Original work published 1945)

Kalsched, D. (1996). The inner world of trauma: Archetypal defenses of the personal spirit. New York, NY: Routledge.

Marieb, E., \& Hoehn, K. (2007). Human anatomy and physiology (7th ed.). Menlo Park, CA: Benjamin/Cummings Science.

Moring, G. (2000). The complete idiot's guide to understanding Einstein. Indianapolis, IN: Alpha Books.

Teilhard de Chardin, P. (1999). Science and Christ. In Pierre Teilhard de Chardin: Writings (U. King, Ed.). Maryknoll, NY: Orbis Books. (Original work published 1968)

Thaut, M., McIntosh, G., \& Hoemberg, V. (2014). Neurobiological foundations of neurologic music therapy: Rhythmic entrainment and the motor system. Frontiers in Psychology, 5, 1185. doi: 10.3389/fpsyg.2014.01185

Ulaby, F., Michielssen, E., \& Ravaioli, U. (2010). Fundamentals of applied electromagnetism (6th ed.). Boston, MA: Prentice Hall.

Von Franz, M. L. (1974). Number and time: Reflections leading toward a unification of depth psychology and physics (A. Dykes, Trans.). Evanston, IL: Northwestern University Press.

Von Franz, M. L. (1992a). Matter and psyche from the point of view of the psychology of C. G. Jung (M. H. Kohn, Trans). In Psyche \& matter (pp. 1-38). Boston, MA: Shambhala. (Original work published 1988)

Von Franz, M. L. (1992b). Time and synchronicity in analytic psychology (J. T. Fraser, Ed.). In Psyche \& matter (pp. 293-323). Boston, MA: Shambhala. (Original work published 1966) 
Vol. 12, No. 1, 2017

Von Franz, M. L. (1998). C. G. Jung: His myth in our time (W. H. Kennedy, Trans.). Toronto, Ontario, Canada: Inner City Books. (Original work published 1972)

Weinberg, S. (1977). The search for unity: Notes for a history of quantum field theory. Daedalus, 106(4), 17-35 Retrieved from JSTOR 20024506. 